\title{
$\gamma$-secretase inhibitor inhibits bladder cancer cell drug resistance and invasion by reducing epithelial-mesenchymal transition
}

\author{
YIBING WANG $^{1}$, GONGXIAN WANG $^{1,2}$, XIALI ZHANG ${ }^{5}$, XIAOCHENG ZHOU ${ }^{1}$, \\ ZHIHUAN LIU ${ }^{1}$, LIANG HUANG ${ }^{1}$, RENSHENG LIU ${ }^{1}$, BIN LANG $^{3}$, XIAOYUAN XU ${ }^{4}$, \\ WEIPENG LIU ${ }^{1}$, LONGLONG FU ${ }^{1}$ and BIN FU ${ }^{1,2}$ \\ ${ }^{1}$ Department of Urology, The First Affiliated Hospital of Nanchang University; ${ }^{2}$ Jiangxi Institute of Urology, Nanchang, \\ Jiangxi 330006; ${ }^{3}$ School of Health Sciences, Macau, China Polytechnic Institute, Macau SAR 999078; \\ ${ }^{4}$ Department of Key Laboratory of System Bio-Medicine of Jiangxi, Medical College of Jiujiang University, Jiujiang, \\ Jiangxi 332000; ${ }^{5}$ Department of Laboratory Animal Science, Nanchang University, Nanchang, Jiangxi 330006, P.R. China
}

Received June 5, 2014; Accepted February 23, 2015

DOI: $10.3892 / \mathrm{mmr} .2015 .3750$

\begin{abstract}
A previous study by our group demonstrated that the expression levels of Notch 1 and Jagged 1 in bladder cancer cells was significantly lower compared with those in normal bladder mucosa, while the expression levels of Notch 1 and Jagged 1 in invasive bladder cancer were higher compared with those in superficial bladder cancer. The present study investigated the effect of the Notch signaling pathway on the drug resistance and invasiveness of bladder cancer cells. It was demonstrated that complete inhibition of the Notch signaling pathway induced significant morphological changes and inhibited cell proliferation and migration $(\mathrm{P}<0.05)$. Reverse transcription quantitative polymerase chain reaction and western blot analyses revealed that the mRNA and protein expression levels of E-cadherin were upregulated $(\mathrm{P}<0.05)$ and the mRNA and protein expression levels of $\mathrm{N}$-cadherin, vimentin and $\alpha$-smooth muscle actin were downregulated $(\mathrm{P}<0.05)$. The present study concluded that complete inhibition of the Notch signaling pathway inhibited cell proliferation and invasion, and reduced drug resistance in bladder cancer cells, a phenomenon which may be associated with the inhibition of the epithelial-mesenchymal transition.
\end{abstract}

\section{Introduction}

Bladder cancer is the most ubiquitous malignant urinary tumor, and is susceptible to recurrence, invasion and metastasis. However, there are only a few studies describing the mechanisms of invasion and metastasis (1). Investigations into

Correspondence to: Professor Bin Fu, Department of Urology, The First Affiliated Hospital of Nanchang University, 17 Yongwaizhen Road, Nanchang, Jiangxi 330006, P.R. China

E-mail: fubinncu@gmail.com

Key words: bladder cancer, $\gamma$-secretase inhibitor, notch signal, epithelial-mesenchymal transition the epithelial-mesenchymal transition (EMT) have provided an increased understanding of the invasion and metastasis of cancer (2-4). The EMT is a biological process, which occurs under specific conditions and interacts with the basement membrane, in which epithelial cells gradually transform into cells with mesenchymal properties. Cancer cells undergoing the EMT process are depolarized and transformed, which enables them to invade and metastasize, accompanied by the inhibition of apoptosis and degradation of the extracellular matrix (5-7). In a previous study by our group, it was demonstrated that the Notch signaling pathway had an anti-tumorigenic function in superficial bladder cancer (8). The expression levels of Notch 1 and Jagged 1 in bladder cancer were significantly lower compared with those in normal bladder mucosa, while the expression levels of Notch 1 and Jagged 1 in invasive bladder cancer were higher compared with those in superficial bladder cancer (9). Based on these previous studies, the present study hypothesized that the Notch signaling pathway is important in the invasion and metastasis of bladder cancer. In the preset study, the Notch signaling pathway was completely inhibited in the bladder cancer cell lines T24, 5637 and J82 using a $\gamma$-secretase inhibitor (GSI). The cellular morphology, drug resistance and invasiveness were subsequently analyzed. The effect of the Notch signaling pathway on the invasion and drug resistance of bladder cancer was assessed by measuring the alterations in the expression levels of the molecular biomarkers associated with EMT, with the aim of determining whether Notch signaling modified urinary tumor invasion and drug resistance by affecting the EMT.

\section{Materials and methods}

Cell culture. T24 and 5637 cell lines (Shanghai Cell Bank, Chinese Academy of Sciences, Shanghai, China) were cultured in RPMI-1640 medium (Beijing Solarbio Science \& Technology, Beijing, China), supplemented with 10\% fetal bovine serum (FBS; Beijing TransGen Biotech Co., Ltd., Beijing, China) and the J82 cell line (Shanghai Cell Bank, Chinese Academy of Sciences) was cultured in minimum essential medium (Beijing Solarbio Science \& Technology), 
supplemented with $10 \%$ FBS. All cells were maintained at $37^{\circ} \mathrm{C}$ in $5 \% \mathrm{CO}_{2}$. When cells were grown to $90 \%$ confluence, the $5 \mu \mathrm{M} \gamma$-secretase inhibitor (GSI; cat. no. \#565750; Calbiochem, Merck, Darmstadt, Germany) was added for 24 or $48 \mathrm{~h}$ (only for western blot).

RNA and protein extraction. Total RNA was extracted using TRIzol reagent (Invitrogen Life Technologies, Carlsbad, CA, USA), according to the manufacturer's instructions. The RNA quality was measured by distinct $18 \mathrm{~S}, 28 \mathrm{~S}$ and total RNA separated by electrophoresis in agarose gels and the proper ratio of absorbance at 230/280 nm (UV-8000 Double Beam UV/VIS model; Metash Instruments, Shanghai, China).

Total proteins were extracted by radioimmunoprecipitation assay cell lysis reagent supplemented with proteinase and phosphatase inhibitors (Beijing Solarbio Science \& Technology) at $4^{\circ} \mathrm{C}$ for $30 \mathrm{~min}$. The cell extracts were centrifuged at $12,000 \mathrm{xg}$ for $20 \mathrm{~min}$ at $4^{\circ} \mathrm{C}$, and the supernatants containing total proteins were mixed with an equal volume of 5X SDS loading buffer (Beijing Solarbio Science \& Technology). The samples were heated to $95^{\circ} \mathrm{C}$ for $5 \mathrm{~min}$.

Reverse transcription quantitative polymerase chain reaction $(R T-q P C R)$. Total RNA $(1 \mu \mathrm{g})$ was used for RT using a Reverse Transcription system (PrimeScript ${ }^{\mathrm{TM}}$ RT Reagent kit; Takara Bio, Inc., Shiga, Japan), according to manufacturer's instructions. RT-qPCR was performed using $\mathrm{SYBR}^{\circledR}$ Premix Ex TaqTM II (TliRNase H Plus; Takara Bio, Inc.) on the ABI PRISM $^{\circledR} 7500$ real-time PCR system (Applied Biosystems, Life Technologies, Thermo Fisher Scientific, Waltham, MA, USA), with $\beta$-actin as an internal control. Thermocycling was performed in a final volume of $20 \mu \mathrm{l}$ consisting of 40 cycles at $95^{\circ} \mathrm{C}$ for $5 \mathrm{sec}$ then $55^{\circ} \mathrm{C}$ for $30 \mathrm{sec}$, following an initial denaturation step at $95^{\circ} \mathrm{C}$ for $10 \mathrm{sec}$. The sequences of the PCR primers of E-cadherin, $\mathrm{N}$-cadherin, vimentin and smooth muscle actin are listed in Table I. The results were analyzed using the $2^{-\Delta \Delta C t}$ method. $\Delta \mathrm{Ct}=$ average gene $\mathrm{Ct}-\Delta$ average of $\beta$-actin Ct. $\Delta \Delta \mathrm{Ct}$ was calculated as follows: $\Delta \Delta \mathrm{Ct}=\Delta \mathrm{Ct}$ of sample group $-\Delta \Delta \mathrm{Ct}$ of control group.

Western blot analysis. The protein concentrations were quantified using a Micro Bicinchoninic Acid Protein Assay kit (Pierce Biotechnology, Inc., Rockford, IL, USA). Identical quantities of total protein from each sample $(30 \mu \mathrm{g})$ were loaded and separated by $12 \%$ SDS-PAGE and transferred onto a polyvinylidene fluoride membrane. The membranes were incubated with the following primary antibodies at $4^{\circ} \mathrm{C}$ overnight: Anti-N-cadherin (1:800; cat. no. ab18203; Abcam, Cambridge, MA, USA), anti-vimentin (1:500; cat. no. 3877; Cell Signaling Technology, Inc., Danvers, MA, USA), anti- $\alpha$-smooth muscle actin $(1: 1,000$; cat. no. P62736; Abgent, Inc., San Diego, CA, USA), anti-E-cadherin (1:800; cat.no. 5296; Cell Signaling Technology, Inc.), and anti- $\beta$-actin (1:1,500; cat. no. ab6276; Abcam). The membranes were then incubated with horseradish peroxidase-conjugated AffiniPure goat anti-rabbit $\lg \mathrm{G}(\mathrm{H}+\mathrm{L})$ secondary antibody (1:10,000; cat. no. ZF-0316-1; ZSGB-BIO, Beijing, China) or horseradish peroxidase-conjugated AffiniPure goat anti-mouse $\lg \mathrm{G}(\mathrm{H}+\mathrm{L})$ secondary antibody $(1: 10,000$; cat. no. ZF-0315-1; ZSGB-BIO) at room temperature for $2 \mathrm{~h}$. The signals were detected using an enhanced chemiluminescence system (cat. no. 32109; Thermo Fisher Scientific) and the films (cat. no. 6535876; Eastman Kodak Company, Rochester, NY, USA) were scanned and analyzed by AlphaEaseFC version 1.1 software (Alpha Innotech, San Leandro, CA, USA).

MTT assay. Cells in the logarithmic growth phase were subcultured in 96-well plates at a cell density of 5,000 cells/well. In each experiment, five wells corresponded to each control group: Mitoxantrone-treated, zero-adjustment wells and control wells. The mitoxantrone wells contained $1,4,16$, 64 and $256 \mathrm{ng} / \mathrm{ml}$ of drug (Sigma-Aldrich, St. Louis, MO, USA). Following $24 \mathrm{~h}$ of drug treatment, $20 \mu \mathrm{l}$ MTT (Beijing Solarbio Science \& Technology) solution was added to each well and the plate was incubated for an additional $4 \mathrm{~h}$, prior to the addition of $150 \mu \mathrm{l}$ dimethylsulfoxide (Beijing Solarbio Science \& Technology) to dissolve the formazan crystals. The absorbance values were measured at $490 \mathrm{~nm}$ (Anthos Zenyth 340rt; Biochrom Ltd., Cambridge, UK). The ratio of inhibition was calculated using the following formula: Inhibition ratio $=\left(1-\mathrm{Ab}_{\text {experiment }} / \mathrm{A} \mathrm{b}_{\text {control }}\right) \times 100 \%$.

Transwell assay. Transwell plates were coated with $40 \mu \mathrm{l}$ $50 \mathrm{mg} / \mathrm{l}$ Matrigel (BD Biosciences, Franklin Lakes, NJ, USA). Cells $(300 \mu \mathrm{l})$ in the logarithmic growth phase were added to the Transwell plates at a final cell density of $1 \times 10^{5}$ cells $/ \mathrm{ml}$. Culture media, supplemented with 20\% FBS (800 $\mu$ l), was added to each well. The plate was incubated at $37^{\circ} \mathrm{C}$ and $5 \% \mathrm{CO}_{2}$ for $24 \mathrm{~h}$. The supernatants were subsequently removed from the Transwells, followed by rinsing, fixation with $2 \mathrm{ml}$ $3.7 \%$ paraformaldehyde and staining with $2 \mathrm{ml} 0.05 \%$ crystal violet (Beijing Solarbio Science \& Technology). The inner cells were removed using a cotton swab and the number of cells, which were below the microporous membrane, were counted using a microscope (XL-71; Olympus Corporation, Tokyo, Japan). The average cell number from 10 randomly selected fields (magnification, x200) was calculated.

Statistical analysis. Values are expressed as the mean \pm standard error and analyzed using SPSS 12.0 (SPSS, Inc., Chicago, IL, USA). Western blot images were semi-quantitatively analyzed using ImageJ version 2.1 software (National Institutes of Health, Bethesda, MD, USA). The means of two samples were analyzed using the independent sample t-test. $\mathrm{P}<0.05$ was considered to indicate a statistically significant difference between values.

\section{Results}

Complete inhibition of the Notch signaling pathway inhibits cell proliferation and induces morphological changes. In order to determine whether the GSI caused morphological changes in bladder cancer cells, T24, 5637 and J82 cells were examined microscopically to assess cell growth and morphological changes following treatment with GSI for $24 \mathrm{~h}$ (Fig. 1). Treatment with GSI significantly reduced the cell density. Intercellular junction formation was also reduced, with the majority of cells exhibiting a shrunken appearance and underwent apoptosis. 
Table I. Primer sequences for polymerase chain reaction amplification.

\begin{tabular}{lll}
\hline Gene & \multicolumn{1}{c}{ Sequence } & Product size (bp) \\
\hline E-cadherin & F: 5'-AAGGCACAGCCTGTCGAAGCA-3' & 167 \\
& R: 5'-ACGTTGTCCCGGGTGTCATCCT-3' \\
N-cadherin & F: 5'-TGCGCGTGAAGGTTTGCCAGT-3' \\
& R: 5'-TGGCGTTCTTTATCCCGGCGT-3' \\
Vimentin & F: 5'-ACCGCACACAGCAAGGCGAT-3' \\
& R: 5'-CGATTGAGGGCTCCTAGCGGTT3' \\
$\alpha$-smooth muscle actin & F: 5'-TGCCCCATGCCATCATGCGT-3' \\
& R: 5'-TGCGGCAGTGGCCATCTCAT-3' \\
$\beta$-actin & F: 5'-AGCGAGCATCCCCCAAAGTT-3' & 132 \\
& R: 5'-GGGCACGAAGGCTCATCATT-3' & 322 \\
\hline
\end{tabular}

F, forward; R, reverse.



Figure 1. Cell growth and morphological changes induced by inhibition of the Notch signaling pathway in (A) T24, (B) 5637 and (C) J82 cells (magnification, x200). GSI, $\gamma$-secretase inhibitor.

Inhibition of the Notch signaling pathway inhibits the EMT. Following treatment with the GSI to inhibit the Notch signaling pathway, the mRNA expression levels of mesenchymal biomarkers, including $\mathrm{N}$-cadherin, vimentin and $\alpha$-smooth muscle actin, were downregulated compared with those in the control group and there was a significant upregulation of the mRNA expression of E-cadherin (Fig. 2; P<0.05).

Western blot analysis demonstrated that the protein expression levels of $\mathrm{N}$-cadherin, vimentin and $\alpha$-smooth muscle actin were significantly downregulated following treatment with 

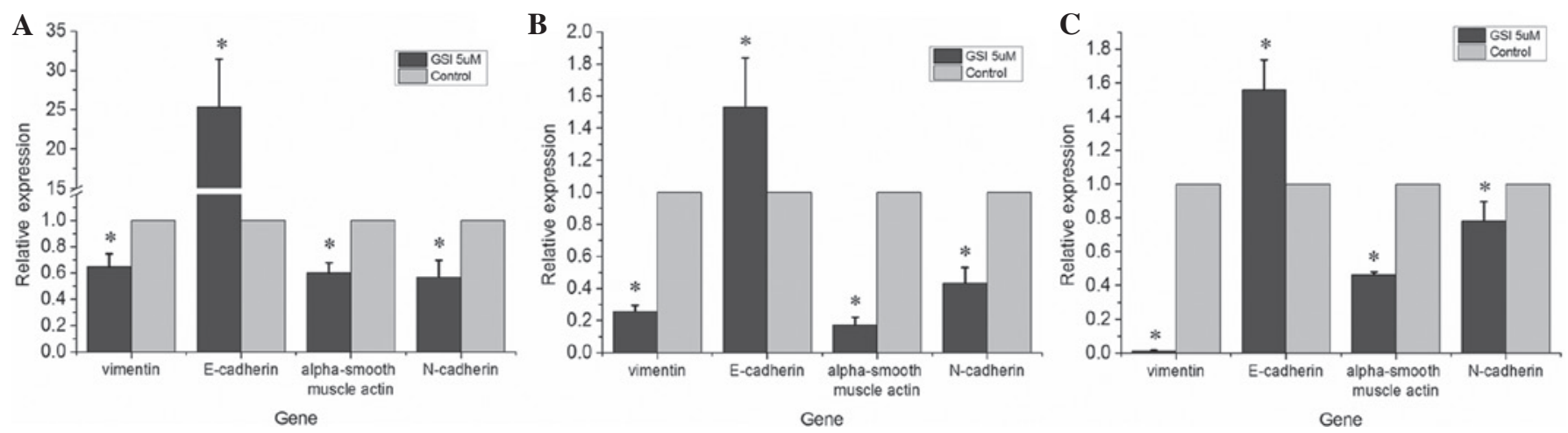

Figure 2. Effect of inhibiting the Notch signaling pathway on mRNA levels of epithelial-mesenchymal transition-associated biomarkers vimentin, E-cadherin, alpha-smooth muscle actin and N-cadherin in (A) T24, (B) 5637 and (C) J82 cells. "P<0.05, vs. control. GSI, $\gamma$-secretase inhibitor.
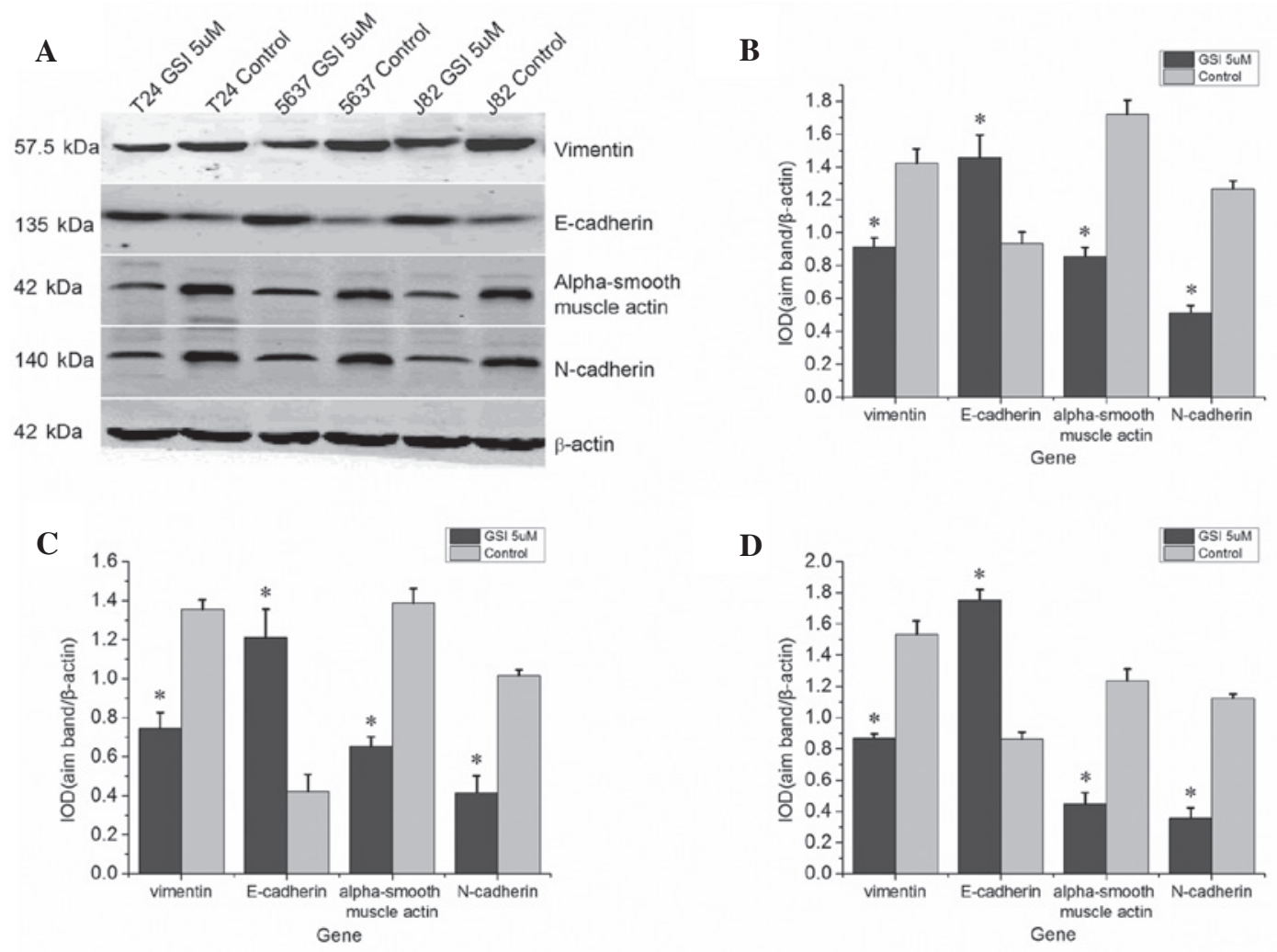

Figure 3. Effect of inhibiting the Notch signaling pathway on the protein expression levels of epithelial-mesenchymal transition-associated proteins vimentin, E-cadherin, alpha-smooth muscle actin and N-cadherin. (A) Western blot and quantification of protein levels in (B) T24, (C) 5637 and (D) J82 cells. "P<0.05, vs. control. GSI, $\gamma$-secretase inhibitor; IOD, integrated optical density.

A

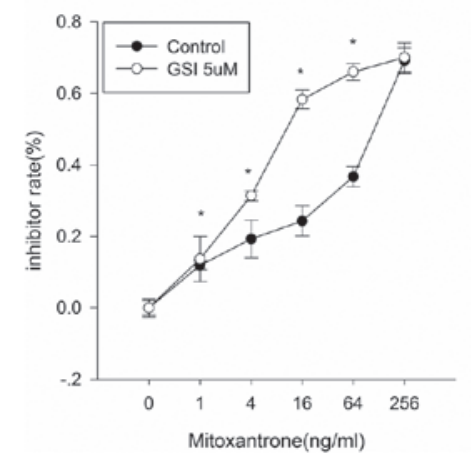

B

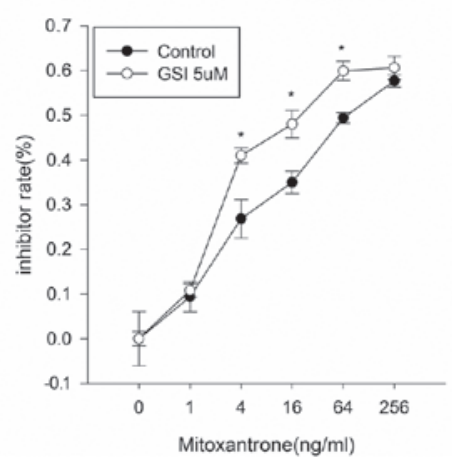

C

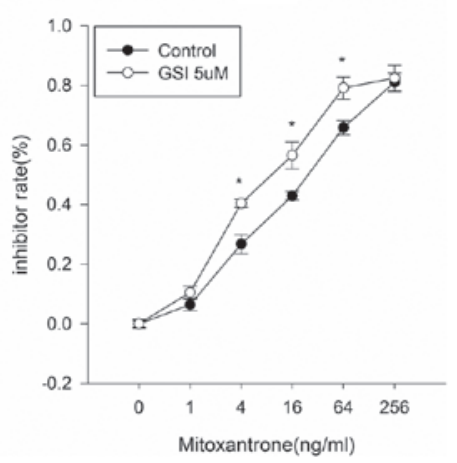

Figure 4. Effect of mitoxantrone and GSI on the growth rate of (A) T24, (B) J82 and (C) 5637 cells. "P<0.05, vs. control. Data is presented as the mean \pm standard deviation. GSI, $\gamma$-secretase inhibitor. 


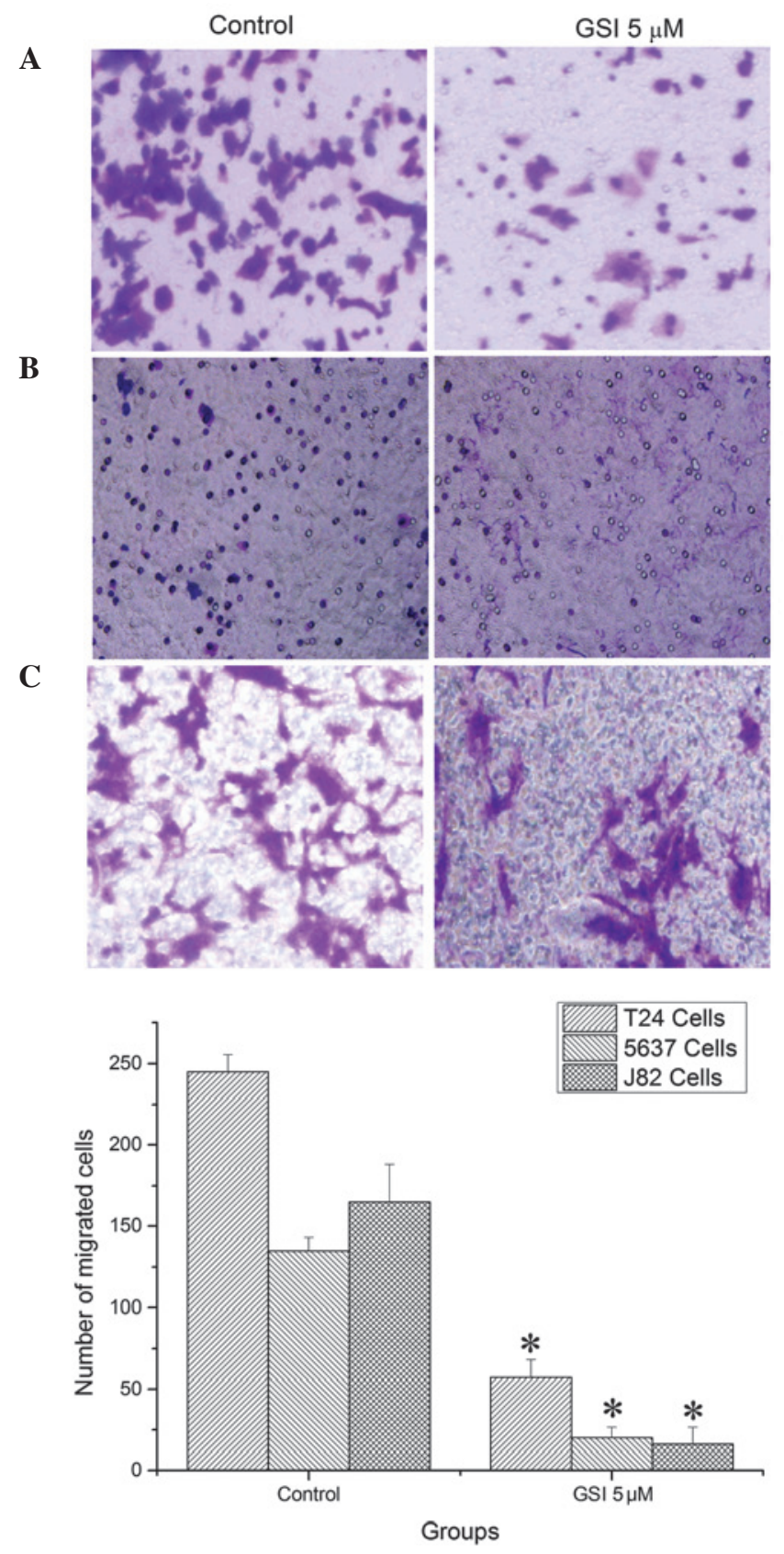

Figure 5. Effect of Notch signaling pathway inhibition on cell invasion in (A) T24, (B) 5637 and (C) J82 cells (crystal violet stain; magnification, $\mathrm{x} 200$ ). "P<0.05, vs. control. GSI, $\gamma$-secretase inhibitor.

GSI compared with those in the control group, whereas the protein expression of of E-cadherin was upregulated (Fig. 3).

This observed downregulation of mesenchymal biomarkers and upregulation of epithelial biomarkers indicated that inhibition of Notch signaling inhibited the EMT.

Inhibition of the Notch signaling pathway reduces the drug resistance and invasiveness of bladder cancer cells. Following treatment with the GSI $(5 \mu \mathrm{M})$ for $48 \mathrm{~h}$, the T24, 5637 and J82 bladder cancer cells were cultured with different concentrations of the bladder cancer therapeutic mitoxantrone and the cell viability was detected using an MTT assay. The results revealed that the GSI-treated cells exhibited an increased sensitivity to mitoxantrone-induced cytotoxicity compared with that of the control (untreated) cells (Fig. 4; $\mathrm{P}<0.05$ ).
Similarly, a Transwell assay demonstrated that the GSI-treated cells were more sensitive to mitoxantrone compared with the untreated cells, as indicated by decreased invasiveness. Treatment with GSI reduced the number of cells which passed through the Transwell membrane, which indicated a deficit in the invasive capacity of those cells which lacked Notch signaling (Fig. 5). Therefore, the present study demonstrated that inhibiting the Notch signaling pathway inhibited the invasion of bladder cancer cells.

\section{Discussion}

Studies have demonstrated that the morbidity of bladder cancer has been increasing in China. Bladder cancer is the most common malignancy of the urinary system, $90 \%$ of which 
are transitional cell carcinoma of the urinary system (5). The proliferation and metastasis of bladder cancer cells involves various transient changes, which involve sequential regulation of a number of different genes and signaling pathways $(5,10,11)$. The Notch signaling pathway and the EMT have been demonstrated to be involved in the proliferation and metastasis of the majority human cancer types (12-15). However, the role of Notch signaling and the EMT in bladder cancer cells remains to be elucidated.

The Notch signaling pathway, a conserved signaling pathway, controls cell proliferation, survival, apoptosis, differentiation and the development and function of various organs $(16,17)$. It has been previously reported that the activation of the Notch signaling pathway predominantly depends upon the activity of GSI (14). GSI, as an effective inhibitor of all Notch receptors, has been used clinically to treat several types of carcinoma $(18,19)$. The present study analyzed the effect of the GSI on the T24, 5637 and J82 bladder cancer cells. A previous study has indicated that Notch 4 activates mouse mammary tumor virus and causes mammary tumors in mice (20). Notch 1 and Notch 2 cooperate with the EIA to transform epithelial cells in common rodent models $(21,22)$. Previous studies have demonstrated that Notch facilitates cell cycle progression and inhibits cell apoptosis (23). Shi et al (8) revealed that the expression of Notch 1 is decreased in non-invasive bladder cancer, while it is highly expressed in invasive bladder cancer. The present study demonstrated a significant inhibition of cell proliferation upon inhibition of the Notch signaling pathway, suggesting that the Notch signaling pathway may trigger carcinogenesis in bladder cancer, particularly those associated with a high expression of Notch 1.

Accumulating evidence has indicated that there is a correlation between the EMT and metastasis, since the EMT can equip cancer cells with an increased migratory ability (24). Grego-Bessa et al (25) demonstrated that inducing the EMT caused a downregulation of expression levels of epithelial markers, including E-cadherin, $\alpha$-catenin and $\beta$-catenin, and an upregulation of mesenchymal biomarkers, including $\mathrm{N}$-cadherin, vimentin, fibronectin, matrix metalloproteinase and $\alpha$-smooth muscle actin. Following complete inhibition of the Notch signaling pathway, T24,5637 and J82 bladder cancer cells exhibited increased expression of E-cadherin and downregulation of the expression levels of $\mathrm{N}$-cadherin, vimentin and $\alpha$-smooth muscle actin, as confirmed by RT-qPCR and western blot analysis. In addition, the invasiveness of bladder cancer cells following inhibition of the Notch signaling pathway was significantly reduced. Consequently, these data suggested that inhibiting the Notch signaling pathway inhibited the EMT in bladder cancer cells, thereby reducing cell invasiveness. A previous study also demonstrated that the Slug molecule was one of the vital components in the process of EMT via the Notch signaling pathway (25). Upregulation of Slug activated the promoter of E-cadherin, resulting in $\operatorname{EMT~}(26,27)$. However, whether the EMT is dependent upon the expression of Slug in bladder cancer remains to be elucidated.

It has been reported that the EMT correlates with drug resistance in cancer, including drug resistance to paclitaxel, vinblastine, oxaliplatin, gemcitabine and epidermal growth factor receptor-targeted agents (28). Shah et al (29) demonstrated that gemcitabine-resistant pancreatic carcinoma cells exhibited the EMT phenotype, alongside downregulation of epithelial markers and upregulation of mesenchymal markers. In addition, activation of the Notch signaling pathway was shown to partially reverse the EMT phenotype $(29,30)$. These data suggested that the activation of Notch signaling may trigger the EMT in cancer cells and, therefore, cause drug resistance. The present study revealed that the inhibition of the Notch signaling pathway in bladder cancer cells caused a higher sensitivity to the anti-cancer drug mitoxantrone as compared with that of the control group. The results indicated that regulation of the EMT by the Notch signaling pathway may be associated with drug resistance in bladder cancer, and that Notch inhibition may be utilized to counteract drug resistance.

In conclusion, treatment with the GSI demonstrated that inhibiting the Notch signaling pathway inhibited the EMT of bladder cancer cells. Inhibiting the Notch signaling pathway triggered reversion of EMT-associated biomarker levels and reduced the invasiveness and drug resistance of bladder cancer cells. These data provided further evidence that there is a clear association between the Notch signaling pathway and the EMT. In further studies it is be necessary to identify the key molecule that regulates the EMT through the Notch signaling pathway, so that the precise signaling regulation network for EMT and the Notch signaling pathway can be determined. Finally, it is necessary to investigate novel molecular mechanisms underlying the genesis, metastasis and drug-resistance of bladder cancer in order to develop novel treatment strategies.

\section{Acknowledgements}

This study was supported by the National Natural Science Foundation of P.R. China (no. 81160272), the Natural Science Foundation of Jiangxi (no. 800GZY0039), the Jiangxi Province Science Foundation for Youths (no. 2010JX02761) and the Science and Technology Development Fund of Macau, China Special Administrative Region (no. 064/2012/A).

\section{References}

1. Ploeg M, Aben KK and Kiemeney LA: The present and future burden of urinary bladder cancer in the world. World J Urol 27: 289-293, 2009.

2. Floor S, van Staveren WC, Larsimont D, Dumont JE and Maenhaut C: Cancer cells in epithelial-to-mesenchymal transition and tumor-propagating-cancer stem cells: Distinct, overlapping or same populations. Oncogene 30: 4609-4621, 2011.

3. Gomes LR, Terra LF, Sogayar MC and Labriola L: Epithelial-mesenchymal transition: Implications in cancer progression and metastasis. Curr Pharm Biotechnol 12: 1881-1890, 2011.

4. Yao D, Dai C and Peng S: Mechanism of the mesenchymal-epithelial transition and its relationship with metastatic tumor formation. Mol Cancer Res 9: 1608-1620, 2011.

5. McConkey DJ, Choi W, Marquis L, Martin F, Williams MB, Shah J, Svatek R, Das A, Adam L, Kamat A, Siefker-Radtke A and Dinney C: Role of epithelial-to-mesenchymal transition (EMT) in drug sensitivity and metastasis in bladder cancer. Cancer Metastasis Rev 28: 335-344, 2009.

6. De Craene B and Berx G: Regulatory networks defining EMT during cancer initiation and progression. Nat Rev Cancer 13: 97-110, 2013.

7. Yilmaz M and Christofori G: EMT, the cytoskeleton, and cancer cell invasion. Cancer Metastasis Rev 28: 15-33, 2009.

8. Shi TP, Ma X, Fu B, Li H, Ai X, Xu H, Ju Z, Wang C, Zhang G, Wang BJ and Zhang X: Expression of Notch signaling in bladder cancer and its relationship with patients' prognosis. Chin J Exp Surg 9: 1305-1307, 2010 (In Chinese). 
9. Wang Z, Li Y, Kong D and Sarkar FH: The role of Notch signaling pathway in epithelial-mesenchymal transition (EMT) during development and tumor aggressiveness. Curr Drug Targets 11: 745-751, 2010.

10. Mills RD, Turner WH, Fleischmann A, Markwalder R, Thalmann GN and Studer UE: Pelvic lymph node metastases from bladder cancer: Outcome in 83 patients after radical cystectomy and pelvic lymphadenectomy. J Urol 166: 19-23, 2001.

11. Kamai T, Tsujii T, Arai K, Takagi K, Asami H, Ito Y and Oshima H: Significant association of Rho/ROCK pathway with invasion and metastasis of bladder cancer. Clin Cancer Res 9: 2632-2641, 2003.

12. Ohashi S, Natsuizaka M, Naganuma $S$, Kagawa $S$, Kimura S, Itoh H, Kalman RA, Nakagawa M, Darling DS, Basu D, Gimotty PA, et al: A NOTCH3-mediated squamous cell differentiation program limits expansion of EMT-competent cells that express the ZEB transcription factors. Cancer Res 71: 6836-6847, 2011.

13. Espinoza I and Miele L: Notch inhibitors for cancer treatment. Pharmacol Ther 139: 95-110, 2013.

14. Ishida T, Hijioka H, Kume K, Miyawaki A and Nakamura N: Notch signaling induces EMT in OSCC cell lines in a hypoxic environment. Oncol Lett 6: 1201-1206, 2013.

15. Li Y, Ma J, Qian X, Wu Q, Xia J, Miele L, Sarkar FH and Wang Z: Regulation of EMT by Notch signaling pathway in tumor progression. Curr Cancer Drug Targets 13: 957-962, 2013.

16. Schwanbeck R, Martini S, BernothK and Just U: The Notch signaling pathway: Molecular basis of cell context dependency. Eur J Cell Biol 90: 572-581, 2011.

17. Borggrefe $T$ and Oswald $F$ : The Notch signaling pathway: Transcriptional regulation at Notch target genes. Cell Mol Life Sci 66: 1631-1646, 2009.

18. Capobianco AJ,Zagouras P,BlaumuellerCM,Artavanis-Tsakonas $\mathrm{S}$ and Bishop JM: Neoplastic transformation by truncated alleles of human NOTCH1/TAN1 and NOTCH2. Mol Cell Biol 17: 6265-6273, 1997.

19. Acloque H, Adams MS, Fishwick K, Bronner-Fraser M and Nieto MA: Epithelial-mesenchymal transitions: The importance of changing cell state in development and disease. J Clin Invest 119: 1438-1449, 2009.

20. Shun XD and Wang HZ: Research progress in bladder cancer markers and its detection methods. J Mod Urol 17: 319-321, 2012
21. Gallahan D, Kozak C and Callahan R: A new common integration region (int-3) for mouse mammary tumor virus on mouse chromosome 17. J Virol 61: 218-220, 1987.

22. Joshi I, Minter LM, Telfer J, Demarest RM, Capobianco AJ, Aster JC, Sicinski P, Fauq A, Golde TE and Osborne BA: Notch signaling mediates $\mathrm{G} 1 / \mathrm{S}$ cell-cycle progression in T cells via cyclin D3 and its dependent kinases. Blood 113: 1689-1698, 2009.

23. Shi TP, Xu H, Wei JF, Ai X, Ma X, Wang BJ, Ju ZH, Zhang GX, Wang C, Wu ZQ, Zhang X, et al: Association of low expression of notch-1 and jagged-1 in human papillary bladder cancer and shorter survival. J Urol 180: 361-366, 2008.

24. Meng F and Wu G: The rejuvenated scenario of epithelial-mesenchymal transition (EMT) and cancer metastasis. Cancer Metastasis Rev 31: 455-467, 2012.

25. Grego-Bessa J, Díez J, Timmerman L and de la Pompa JL: Notch and epithelial-mesenchyme transition in development and tumor progression: Another turn of the screw. Cell Cycle 3: 718-721, 2004.

26. Leong KG, Niessen K, Kulic I, Raouf A, Eaves C, Pollet I and Karsan A: Jagged1-mediated Notch activation induces epithelial-to-mesenchymal transition through Slug-induced repression of E-cadherin. J Exp Med 204: 2935-2948, 2007.

27. Niessen K, Fu Y, Chang L, Hoodless PA, McFadden D and Karsan A: Slug is a direct Notch target required for initiation of cardiac cushion cellularization. J Cell Biol 182: 315-325, 2008.

28. Sabbah M, Emami S, Redeuilh G, Julien S, Prevost G, Zimber A Ouelaa R, Bracke M, De Wever O and Gespach C: Molecular signature and therapeutic perspective of the epithelial-to-mesenchymal transitions in epithelial cancers. Drug Resist Updat 11: 123-151, 2008.

29. Shah AN, Summy JM,Zhang J,Park SI, Parikh NU and Gallick GE: Development and characterization of gemcitabine-resistant pancreatic tumor cells. Ann Surg Oncol 14: 3629-3637, 2007.

30. Wang Z, Li Y, Kong D, Banerjee S, Ahmad A, Azmi AS, Ali S, Abbruzzese JL, Gallick GE and Sarkar FH: Acquisition of epithelial-mesenchymal transition phenotype of gemcitabine-resistant pancreatic cancer cells is linked with activation of the notch signaling pathway. Cancer Res 69: 2400-2407, 2009. 